\title{
Influence on Sales Channels of Supply Chain Structure under Power Balance
}

\author{
Dapeng Yang ${ }^{1, a}$, Meidan Xiao ${ }^{2, b}$, Mingyang Chen ${ }^{3, \mathrm{c}}$ \\ ${ }^{1}$ College of Information and Management Science, Henan Agricultural University, Zhengzhou, \\ 450002, China \\ ${ }^{2}$ College of Information and Management Science, Henan Agricultural University, Zhengzhou, \\ 450002, China \\ ${ }^{3}$ College of Information and Management Science, Henan Agricultural University, Zhengzhou, \\ 450002, China \\ aemail: yangdapeng081219@126.com, bemail: xiaomeidan_fujian@126.com
}

Keywords: Dual-channel; Pricing decisions; Substitutability; Equilibrium

\begin{abstract}
This paper considered a supply chain system with two manufacturers, each producing a single substitutable product. The products are sold through the common retailer or the manufacturer's online sales channel. The purpose of this paper is to analyze the equilibrium pricing strategy and profits under different channel combinations on both sides of the manufacturer and the retailer, using the Nash power between manufacturer and retailer, and to explore the advantages and disadvantages of the manufacturers developing the online sales channel.
\end{abstract}

\section{Introduction}

Currently, online shopping is the second best way to buy stuff after the traditional retail channel for more and more consumers. According to the statistical report of the China Internet Network Work Information Center (CNNIAC) in 2013, the scale of users of Internet shopping in China was 3.02 hundred million, and the usage rate of Internet shopping has increased to 48.9\%, which was six percentage points more than 2012. More and more tradition manufacturer companies, such as Hewlett-Packard, IBM, Eastman Kodak, Nike and Apple etc., have achieved online sales by means of online technology. But can the online structure bring excess profits to the supply chain members?

In a market channel, both the manufacturer and the retailer have power, defined by EI-Ansary and Stern(1972)as the ability of one channel member to control the decision variables in the marketing strategy of another member in a given channel at a different level of distribution(Pan 2010).Different power structures appear in real market. For example, as a powerful manufacturer, Microsoft and Intel always have more dominant right than their bottom strands. On the other hand, some retailers are more powerful in cases, such as Carrefour and Wal-Mart, they are playing a more significant role than their upstream firm in some market chains, they reduce the retail price of the product, extrusion manufacturer's profits to ensure that its profits. However, with the competition in the market becoming white-hot, the ideas like "whether manufacturer is leading or retail terminal for the king" are difficult to adapt to the objective environment, so the power balance in supply chain structure has been developed.

The literature refers to the study of dual- channel structure and product substitutability has been rich. On the choice of the two-channel structure, Park and Keh (2003) compared the chain profits under different rights structures show that adopting mixed channels will help manufactures to increase the products' overall demand and their own profit, enhance the overall performance of the supply chain and social welfare. Taking into account of the degree of consumer's acceptance in direct-marketing channels, Chiang (2003) further analyzed the impact of the profit for the supply chain members under the direct-marketing channels, pointing out that even with no sales through the online channels; the direct-marketing channels can increase the profits. Cai (2010) compared the influences of four channels--single direct-marketing channels, single retail channels, direct sales channels combined with retail channels, dual-retailer channels with manufacturer, retailers and the 
whole supply chain and came up with the conclusion that the dual-channel combining direct-marketing channel and retailer channel gain more profit for manufactures than the single direct-marketing channel. In the research about substitutable products supply chain, most of it has focused on inventory and pricing problems. For related surveys, see Stavrulaki(2011) studied a retailer's inventory strategy for two products, which are substitutable and have inventory dependent demand. Xia (2011) considered competition between two coexisting suppliers in a two-echelon supply chain, where each supplier offers one type of the two substitutable products to multiple buyers. Zhao (2014) analyzed the effects of the two manufacturers' different competitive strategies and the channel members' different power structures on the optimal pricing decisions, but it doesn't consider the online channel. Different from the above studies, this paper focuses on the two manufacturers and a single retailer with the online sale channel, adopting the Nash power strategy and considers the effect of the products' substitutability on the online channel.

\section{Problem Description}

As figure 1, we considered two types supply chain structures: the traditional model (Model A), and online model (Model B and Model C). In Model A, the products are only available to consumers by the retailer. However, in Model B or Model C, manufacturers and retailer can provide products to the consumers at the same time.

Following signs need to be defined during modeling in this paper:

$r$ : the proportion of basic demand in online channel,

$p_{i}$ : the unit retail price of product $(i=1,2)$, where $p_{1}$ represents the product price of manufacturer $M_{1}$, and $p_{2}$ represents the product price of manufacturer $M_{2}$.

$p_{o i}:$ the unit retail price of product under online channel

$w_{i}$ : the unit wholesale price of product $(i=1,2)$, where $w_{1}$ represents the wholesale price of manufacturer $M_{1}$, and $w_{2}$ represents the wholesale price of manufacturer $M_{2}$.

$D_{i}$ : the demand of product ( $i=1,2$ ), where $D_{1}$ represents the product demand of manufacturer $M_{1}$, and $D_{2}$ represents the product demand of manufacturer $M_{2}$.

$D_{o i}$ : the demand of product under the online channels.

$\theta$ : the products substitutability, where $\theta=0$, the products are purely monopolistic and where $\theta$ goes to 1 , the products converge to purely substitutable.

$a_{i}$ :is the base demand of product $i$.

$\Pi_{m i}$ : the profits in traditional channels for manufacture $i$.

$\Pi_{o i}$ : the profits in online channels for manufacture $i$.

$\Pi_{i}$ : the profits in the whole supply chain for manufacture $i$.

$\Pi_{r}$ :the profits for the retailer.
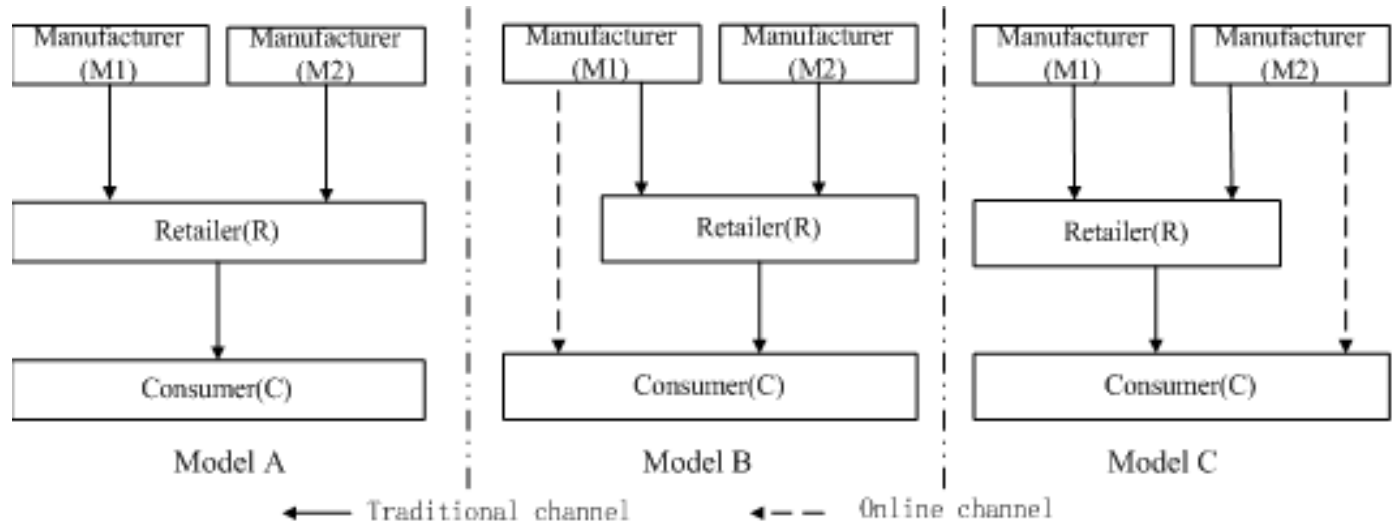

Figure.1. Supply chain structures in online channels and retail channels

For simplicity, we assume that the manufacturer's production costs and online channels operating 
costs are zero, and assume the market demand for the basic product $i=(1,2)$ is $a_{i}=1$, being used to reflect that the two channels are symmetrical. Since the Model B and Model C are symmetric channel structures, we only consider one.

This paper adopted the consumer utility function of Cai, established the demand function according to the consumer utility function:

$$
U \equiv \sum_{i=1,2}^{n}\left(a_{i} D_{i}-\frac{D_{i}^{2}}{2}\right)-\theta D_{1} D_{2}-\sum_{i=1,2} p_{i} D_{i}
$$

can get the demand functions respectively for manufacturer $M_{1}$ and manufacturer $M_{2}$ :

$$
D_{i}=\frac{a_{i}-\theta a_{3-i}-p_{i}+\theta p_{3-i}}{1-\theta^{2}}(i=1,2)
$$

Then, the profit functions of manufacturers and their online channels and retailer can be expressed as:

$$
\Pi_{m i}=w_{i} D_{i}, \Pi_{o i}=p_{o i} D_{o i}, \Pi_{i}=\Pi_{m i}+\Pi_{o i}, \Pi_{r}=\sum_{i=1}^{2}\left(p_{i}-w_{i}\right) D_{i}
$$

\section{Analytical Results}

In the MA structure, two manufacturers offer their products to the retailer; neither open online direct-marketing channels, and consumers can only purchase products through retailer $\mathrm{R}$. At this Nash Game is: manufacturer $M_{1}$ and $M_{2}$ develop their wholesale price $w_{1}$ and $w_{2}$.And retail $\mathrm{R}$ develops retail prices as $p_{1}$ and $p_{2}$ simultaneously.According to equation (2), we know that the demand of the product is:

$$
D_{1}=\frac{1-\theta-p_{1}+\theta p_{2}}{1-\theta^{2}}, D_{2}=\frac{1-\theta-p_{2}+\theta p_{1}}{1-\theta^{2}},
$$

therefore the profit function for retailer $\mathrm{R}$ is:

$$
\Pi_{r}=\left(p_{1}-w_{1}\right) D_{1}+\left(p_{2}-w_{2}\right) D_{2}
$$

The profit function for manufacture is : $\Pi_{i}^{M A}=\Pi_{m i}^{M A}=w_{i} D_{i} \quad(i=1,2)$

Lemma 1: Under the MA structure, namely: two manufacturers offer their own products to the retailer, but neither open online direct-marketing channels, and consumers can only purchase products through retailers $\mathrm{R}$, thus the optimal wholesale price and sales price are: $w_{i}^{\mathrm{MA}}=\frac{1-\theta}{3-\theta}$, $p_{i}^{M A^{*}}=\frac{2-\theta}{3-\theta}$.

In MB structure, manufacturers $M_{1}$ and $M_{2}$ develop wholesale prices as $w_{1}$ and $w_{2}$, retail R develop retail prices as $p_{1}$ and $p_{2}$ at the same time, manufacturer $M_{1}$ develops its price in online channel $p_{o 1}$.According to Choi SC (1991) and Choi SC demand function model (1996) in his paper, combined with the demand function model we get before; there is a demand function after the introduction of direct sales channels as follows:

$$
D_{(i, o i)} \equiv \begin{cases}\frac{(1-r)(1-\theta)-p_{1}+\theta\left(p_{2}+p_{o 1}\right)}{1-\theta^{2}}(i=1) \\ \frac{(1-r)(1-\theta)+\theta\left(p_{1}+p_{o 1}\right)-p_{2}}{1-\theta^{2}}(i=2) \\ \frac{r(1-\theta)+\theta\left(p_{1}+p_{2}\right)-p_{o 1}}{1-\theta^{2}} & (o i=o 1)\end{cases}
$$


The profits function for manufactures is:

$$
\Pi_{1}^{M B}=\Pi_{m 1}^{M B}+\Pi_{o 1}^{M B}=w_{1} D_{1}+p_{o i} D_{o 1}, \Pi_{2}^{M B}=\Pi_{m 2}^{M B}=w_{2} D_{2}(5)
$$

Lemma 2: Under the MB structure, namely: two manufacturers offer their own products to retailers, but in the market, only manufacture $M_{1}$ develops online direct-marketing channels, and consumers can purchase products through retailer $\mathrm{R}$ or manufacture $M_{1}$, thus the optimal wholesale price and sales price are:

$$
\begin{aligned}
w_{1}^{M B^{*}} & =\frac{(\theta-1)\left(4 \theta-5 \theta^{2}+\theta^{3}-6+r\left(6-13 \theta+13 \theta^{2}\right)\right)}{2\left(9-9 \theta-13 \theta^{2}+7 \theta^{3}+2 \theta^{4}\right)} \\
w_{2}^{M B^{*}} & =\frac{(\theta-1)\left(10 \theta-5 \theta^{2}-6+r\left(6-13 \theta+8 \theta^{2}\right)\right)}{2\left(9-18 \theta+5 \theta^{2}+2 \theta^{3}\right)} \\
p_{1}^{M B^{*}} & =\frac{(\theta-1)\left(2 \theta+3 \theta^{2}+\theta^{3}-12+r\left(12-11 \theta+\theta^{2}\right)\right)}{2\left(9-9 \theta-13 \theta^{2}+7 \theta^{3}+2 \theta^{4}\right)} \\
p_{2}^{M B^{*}} & =\frac{(\theta-1)\left(\theta+4 \theta^{2}-\theta^{3}-6+2 r\left(3-2 \theta-2 \theta^{2}+\theta^{3}\right)\right)}{9-9 \theta-13 \theta^{2}+7 \theta^{3}+2 \theta^{4}} \\
p_{o 1}^{M B^{*}} & =\frac{(1-\theta)(3+\theta)\left((5-3 \theta) \theta+r\left(3-9 \theta+4 \theta^{2}\right)\right)}{2\left(9-9 \theta-13 \theta^{2}+7 \theta^{3}+2 \theta^{4}\right)}
\end{aligned}
$$

It should be noted that the retail price is not lower than the wholesale price, namely: $w_{i}^{M B^{*}} \leq p_{i}^{M B^{*}}$;Meanwhile, non-negative retail prices and wholesale prices: $\theta \in(0, \sqrt{7}-2)$.

\section{Comparisons and Managerial Implications}

In this section, we give the equilibrium solutions for the two models(as shown in Table 1) and explore which one is better.

Table.1.The equilibrium solutions for the two models

\begin{tabular}{ccc}
\hline variable & MA & MB \\
\hline$w_{i}^{*}$ & $\frac{1-\theta}{3-\theta}$ & $w_{1}^{*}=\frac{(\theta-1)\left(4 \theta-5 \theta^{2}+\theta^{3}-6+r\left(6-13 \theta+13 \theta^{2}\right)\right)}{2\left(9-9 \theta-13 \theta^{2}+7 \theta^{3}+2 \theta^{4}\right)}$ \\
& $w_{2}^{*}=\frac{(\theta-1)\left(10 \theta-5 \theta^{2}-6+r\left(6-13 \theta+8 \theta^{2}\right)\right)}{2\left(9-18 \theta+5 \theta^{2}+2 \theta^{3}\right)}$ \\
& $p_{1}^{*}=\frac{(\theta-1)\left(2 \theta+3 \theta^{2}+\theta^{3}-12+r\left(12-11 \theta+\theta^{2}\right)\right)}{2\left(9-9 \theta-13 \theta^{2}+7 \theta^{3}+2 \theta^{4}\right)}$ \\
$p_{i}^{*}$ & $p_{2}^{*}=\frac{(\theta-1)\left(\theta+4 \theta^{2}-\theta^{3}-6+2 r\left(3-2 \theta-2 \theta^{2}+\theta^{3}\right)\right)}{9-9 \theta-13 \theta^{2}+7 \theta^{3}+2 \theta^{4}}$ \\
& $p_{o 1}^{*}=\frac{(1-\theta)(3+\theta)\left((5-3 \theta) \theta+r\left(3-9 \theta+4 \theta^{2}\right)\right)}{2\left(9-9 \theta-13 \theta^{2}+7 \theta^{3}+2 \theta^{4}\right)}$ \\
& $D_{1}^{*}=\frac{6-10 \theta+3 \theta^{3}+r\left(10 \theta+\theta^{2}-4 \theta^{3}-6\right)}{2\left(9-9 \theta-13 \theta^{2}+7 \theta^{3}+2 \theta^{4}\right)}$ \\
$D_{i}^{*}$ & $D_{2}^{*}=\frac{6-10 \theta+5 \theta^{2}+r\left(+13 \theta-8 \theta^{2}-6\right)}{2\left(9-9 \theta-13 \theta^{2}+7 \theta^{3}+2 \theta^{4}\right)}$ \\
& $D_{o 1}^{*}=\frac{\theta\left(9-9 \theta+\theta^{2}\right)+r\left(9-27 \theta+17 \theta^{2}\right)}{2\left(9-9 \theta-13 \theta^{2}+7 \theta^{3}+2 \theta^{4}\right)}$ \\
\hline
\end{tabular}

Proposition1: only when $\theta \in(0, \sqrt{7}-2)$ can two types of structural patterns exist; when $\theta \in(\sqrt{7}-2,1)$, only Model A exists in the market. 
The proposition result shows that: product substitutability is crucial to the differences of channel structures, online channel may not be established under all circumstances without considering the product substitutability.

Proposition2: After establishing online channel,manufacturer's profit is a monotonous increasing function of product substitutability $\theta$, while manufacturer's profit is a monotony decrease function of $\theta$ under traditional channel MA.

The proposition result shows that: manufacturer's profit is affected by channel structure and product substitutability, under high product substitutability, establishing online channel can bring higher profits to manufacturers; when the product substitutability is low, manufactures more prefer traditional channel. Figure(2) verifies this conclusion when $r=0.2$ :

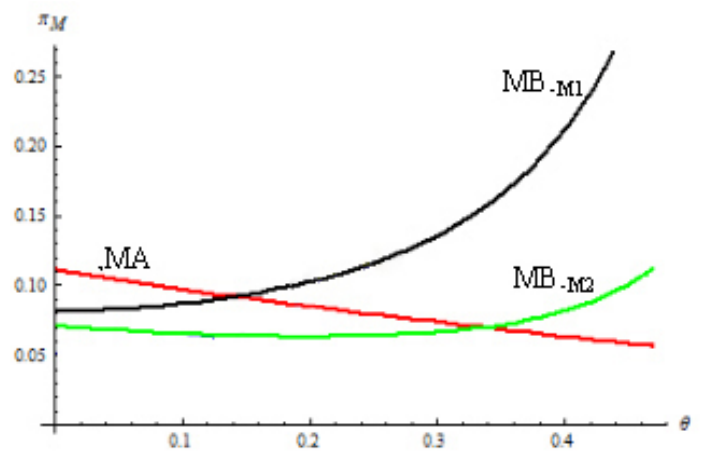

Figure.2.The comparison of manufacture's profit under MA and MB when $r=0.2$

Proposition 3: when $\theta \in(0, \sqrt{7}-2)$, For $M_{2}$ who doesn't establish online channel, when $r=\frac{9 \theta^{3}-15 \theta^{2}}{45 \theta-37 \theta^{2}+8 \theta^{3}-18}$, it gets the same profit under structure MB and MA, when $r<\frac{9 \theta^{3}-15 \theta^{2}}{45 \theta-37 \theta^{2}+8 \theta^{3}-18}$, it gets more profit under $\mathrm{MB}$ than that under MA, when $r>\frac{9 \theta^{3}-15 \theta^{2}}{45 \theta-37 \theta^{2}+8 \theta^{3}-18}$, it gets more profits under MA .

In addition, under Model B structure, Manufacturer $M_{1}$ who opens up online channel gets more profits than manufacturer $M_{2}$ who doesn't establish network channel.

$$
\begin{aligned}
& \Delta_{\Pi}^{M B}=\Pi_{1}^{M B^{*}}-\Pi_{2}^{M B^{*}}=\frac{(1-\theta)^{2}\left(\theta^{2} B_{1}+2 r \theta B_{2}+r^{2} B_{3}\right)}{4(1+\theta)^{2}\left(-9+18 \theta-5 \theta^{2}-2 \theta^{3}\right)^{2}}>0 \\
& B_{1}=104 \theta+7 \theta^{2}-6 \theta^{3}-165, \quad B_{2}=318 \theta-109 \theta^{2}-28 \theta^{3}+4 \theta^{4}-117, \\
& B_{3}=396 \theta-525 \theta^{2}+78 \theta^{3}+56 \theta^{4}-81 .
\end{aligned}
$$

The proposition shows that: It is not a bad thing when manufacturer's competitor establish online channel, the demand of online channel should be further considered, if the proportion of online channel is out of a certain range, the manufacturer's profit will be affected. While for the manufacturer who establish online channel, his profit is higher than his competitors' all the time. Therefore, manufacturer who is the first to establish online channel can get more advantage than his competitors.

Proposition 4: On the basis of proposition3, after manufacturer $M_{1}$ establish network channel, his profit of traditional channel is affected by product substitutability $\theta$ and network distribution ratio $r$, that is $\Delta_{m 1}=\Pi_{m 1}^{M B}-\Pi_{m 1}^{M A}$. Figure (3) verifies this conclusion when $\theta=0.1, \theta=0.3$. 


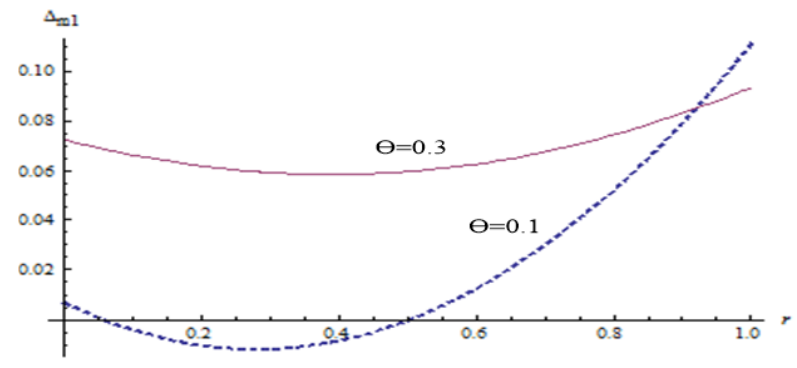

Figure.3.The comparison of $\Lambda_{m 1}$ when $\theta=0.1, \theta=0.3$

\section{Conclusion}

This paper show that establishing online channel can bring high profit to manufacturer and retailer when product substitutability is high, while when product substitutability is low, even there is almost no substitutability between products, traditional channel is the best for manufacturer, retailer and the entire Supply Chain System. Also when competitor establish online channel, the profit of manufacturer who doesn't establish online channel won't decrease because of the change of market structure, under the influence of online channel distribution rate. Its profit will exceed that in former market structure.

This paper only discusses two manufactures and one retailer, so there are still some deficiencies. In the future, it can be extended to multiple manufacturers and retailers. Besides, this paper considers all of the supply chain cost as zero; future research should consider supplier's operating costs in traditional channels and online channels.

\section{Acknowledgement}

In this paper, the research was sponsored by the Soft Science Foundation of Henan Province (Project No. 142400410044).

\section{References}

[1] http://news.xinhuanet.com/tech/2014-01/16/c_126015636.htm.

[2] El-Ansary A I, Stern L W. Power Measurement in the Distribution Channel[J]. Journal of Marketing Research (JMR), 1972, 9(1).

[3] Park S Y, Keh H T. Modelling hybrid distribution channels: A game-theoretic analysis. Journal of Retailing and Consumer Services, 2003, 10(3): 155-167.

[4] Chiang W K, Chhajed D, Hess J D. Direct marketing, indirect profits: A strategic analysis of dual-channel supply-chain design [J]. Management Science, 2003, 49(1): 1-20.

[5] Stavrulaki E. Inventory decisions for substitutable products with stock-dependent demand [J]. International Journal of Production Economics, 2011, 129(1): 65-78.

[6] Cai G G. Channel selection and coordination in dual-channel supply chains [J]. Journal of Retailing, 2010, 86(1): 22-36.

[7] Xia Y. Competitive strategies and market segmentation for suppliers with substitutable products [J]. European Journal of Operational Research, 2011, 210(2): 194-203.

[8] Zhao J, Wei J, Li Y. Pricing decisions for substitutable products in a two-echelon supply chain with firms' different channel powers [J]. International Journal of Production Economics, 2014, 153: 243-25. 